\title{
Intervensi Bagi Orang Tua dalam Mencegah Kekerasan Seksual Anak di Indonesia: Scoping Review
}

\author{
Tetti Solehati ${ }^{\circledR}$, Riezky Fajri Septiani ${ }^{1}$, Rizka Muliani ${ }^{1}$, Selly Amalia Nurhasanah ${ }^{1}$, Sifa \\ Nur Afriani ${ }^{1}$, Sifa Nuraini ${ }^{1}$, Sifva Fauziah"1, Sonia Dwiastuti Pratiwi', Sri Purnama Alam¹, \\ Yanti Hermayanti ${ }^{1}$, Cecep Eli Kosasih ${ }^{1}$, Henny Suzana Mediani ${ }^{1}$ \\ Fakultas Keperawatan, Universitas Padjadjaran Bandung, Indonesia(1) \\ DOI: 10.31004/obsesi.v6i3.1914
}

\begin{abstract}
Abstrak
Kasus kekerasan seksual anak (KSA) di Indonesia meningkat setiap tahunnya. Orangtua berperan penting dalam pendidikan pencegahan KSA. Tujuan penelitian untuk memetakan intervensi bagi orang tua dalam mencegah KSA. Desain penelitian scoping review. Pencarian artikel menggunakan database terkomputerisasi, yaitu: CINAHL EBSCO, PubMed, Pyschoinfo, Google Scholar, Jurnal Unpad, dan pencarian secara manual dengan menggunakan kunci berbahasa Inggris dan Indonesia. Hasil artikel awal didapatkan berjumlah 15.507, kemudian dilakukan penyaringan berdasarkan kriteria inklusi serta dilakukan penilainan artikel sehingga menghasilkan 18 artikel yang memenuhi syarat. Hasil penelitian menunjukan ditemukan ada 6 bentuk intervensi pencegahan KSA yang dapat dilakukan orang tua, yaitu pemberian pendidikan kesehatan seksual pada orangtua, pemberian pendidikan bagi orang tua tentang pencegahan KSA, program pendidikan keluarga, pola asuh orang tua yang baik, optimalisasi peran orang tua, dan hubungan tingkat pendidikan dengan pengetahuan orang tua. Dengan demikian ada beberapa pencegahan KSA yang dapat dilakukan orang tua untuk melindungi anaknya dari KSA.
\end{abstract}

Kata kunci: Anak, Intervensi, Kekerasan seksual, Pencegahan, Orang tua

\begin{abstract}
Cases of child sexual abuse (CSA) in Indonesia is increased every year. Parents have an important role in CSA prevention education. The purpose of the study was to map out interventions for parents in preventing of CSA. The research design was scoping review. Search articles used computerized databases, namely: CINAHL EBSCO, PubMed, Pyschoinfo, Google Scholar, Unpad Journal, and search manually used English and Indonesian keyword. The results showed that from 18 articles, it was found that there were 6 forms of prevention that parents could do, namely providing sexual health education of parents, providing education on prevention of sexual abuse for parents, family education programs, good parenting patterns, optimizing the role of parents, and relationship between education level and parental knowledge. Thus, there are several preventions of CSA that parents can do to protect their children from sexual crimes.
\end{abstract}

Keywords: Children, Intervention, Sexual abuse, Prevention, Parents

Copyright (c) 2022 Tetti Solehati, et al.

$\triangle$ Corresponding author :

Email Address : tetti.solehati@unpad.ac.id (Bandung, Indonesia)

Received 3 July 2021, Accepted 13 December 2021, Published 1 January 2021 
Intervensi Bagi Orang Tua dalam Mencegah Kekerasan Seksual Anak di Indonesia: Scoping Review DOI: $10.31004 /$ obsesi.v6i3.1914

\section{PENDAHULUAN}

Kasus kekerasan seksual di Indonesia mengalami peningkatan setiap tahunnya, dengan korbannya bukan hanya orang dewasa tetapi sudah merambah ke remaja, anak-anak, dan bahkan balita saat ini (Noviana, 2015). Pada tahun 2015, KPAI (Komisi Perlindungan Anak Indonesia) menyatakan bahwa kasus pelecehan seksual sebanyak 1.726 kasus, anakanak mengalami kasus pelecehan seksual sekitar 58\% (Amr, 2016). Berdasarkan data dari Bank Data Perlindungan Anak Komisi Perlindungan Anak Indonesia (KPAI) per 31 Desember 2020 yaitu pada tahun 2018 anak sebagai korban kekerasan seksual yaitu sebanyak 182 korban. Pada tahun 2019 mengalami kenaikan dengan jumlah korban yaitu 190, dan pada tahun 2020 mengalami kenaikan dengan jumlah korban anak yaitu sebanyak 419. Jika dihitung dari 2018 anak sebagai korban kekerasan seksual mengalami peningkatan sebanyak 237 korban (KPAI, 2021)

Anak didefinisikan sebagai asset bangsa yang merupakan generasi penerus, memiliki cita-cita dan harapan untuk membangun bangsanya menjadi lebih baik (Sitompul, 2015). Sudah seharusnya anak-anak mendapatkan perlindungan dari orangtua, keluarga, masyarakat, dan negara (Sitompul, 2015). Anak harus mendapatkan perlindungan khusus terhadap kepentingan fisik maupun mentalnya. Hal ini bertujuan agar anak dapat bertumbuh kembang dengan baik, serta terlindung dari ancaman kejahatan yang membahayakan sesuai dengan Undang-undang nomor 35 tahun 2014 tentang Perlindungan Anak (Ajeng et al., 2018).

Masalah yang sering didapatkan pada anak yaitu kekerasan seksual. Kekerasan seksual pada anak (KSA). Menurut CAST Programme, Child Development Institute, Boyscouts of america; Komnas PA, KSA adalah kerterlibatan seorang anak dalam segala bentuk aktivitas seksual, terjadi sebelum anak mencapai batasan umur tertentu yang ditetapkan oleh hukum negara, dimana orang dewasa atau anak lain yang usianya lebih tua atau orang yang dianggap memiliki pengetahuan lebih dari anak memanfaatkannya untuk kesenangan seksual (Ajeng et al., 2018). KSA melibatkan, membujuk, atau memaksa anak untuk anak untuk berperilaku dalam seksual yang tidak pantas, termasuk sudah terjadi atau masih dalam bentuk usaha tindakan seksual, atau adanya interaksi seksual non-kontak dengan seorang anak oleh orang dewasa (Rohmah et al., 2015).

Hampir dari setiap kasus yang diungkap, pelakunya adalah orang yang dekat korban dan tidak sedikit pula pelakunya adalah orang yang memiliki dominasi atas korban, seperti orang tua dan guru (Noviana, 2015). Terdapat beberapa faktor yang menyebabkan terjadinya KSA, antara lain: faktor rendahnya pendidikan dan ekonomi, fakor lingkungan atau tempat tinggal, faktor minuman keras, faktor teknologi dan peranan korban, serta faktor kelalaian orang tua (Sulastri, 2019). Selain itu faktor emosi yang ada di dalam diri pelaku. Faktor pergaulan yang semakin bebas dan tingkat kontrol masyarakat yang rendah juga memiliki peranan dalam terjadinya KSA (Subrahmaniam, 2019).

Dampak buruk pada anak sebagai korban KSA diantaranya adalah post-traumatic stress disorder (PTSD) (Ajeng et al., 2018), merasa rendah diri, ada kebencian terhadap laki-laki, merasa tidak aman, dan trauma hingga remaja (Rakhmawati., 2016), depresi, kecemasan, perilaku seksual yang tidak pantas, kehilangan kemampuan bersosialiasi, gangguan kognitif, masalah citra tubuh, dan penyalahgunaan zat (WHO, 2017).

Orangtua memainkan peran penting dalam pendidikan pencegahan KSA, tetapi mayoritas masih bingung bagaimana memberitahu atau menjelaskan kepada anaknya (Utami \& Noorratri, 2021). Sayangnya, banyak orang tua yang belum memahami dan menyadari tentang pentingnya pencegahan KSA. Mereka juga banyak yang bingung bagaimana menyampaikan topik seksual kepada anak yang masih dianggap tabu oleh masyarakat Indonesia. Oleh karena itu orang tua harus diajarkan bagaimana menjalin komunikasi terbuka pengungkapan diri (self disclosure) dengan anaknya dengan cara orang tua bercerita terlebih dahulu dan orang tua juga harus sabar mendengarkan anak saat berbicara.. Orang tua seharusnya menyediakan waktu walaupun sibuk untuk tetap berkomunikasi dengan anaknya agar bisa mendeteksi dini apa yang dirasakan oleh anak (M. Handayani, 2017). Upaya 
pencegahan KSA dapat dilakukan melalui permainan, pembelajaran, boneka pertunjukan, drama, dan atau kelompok diskusi (Müller \& Fingerle, 2014). Beberapa penelitian menyatakan bahwa program pencegahan kekerasan seksual adalah cara yang efektif untuk mencegah kekerasan seksual terhadap anak (Bustamante et al., 2019). Pencegahan KSA merupakan salah satu bentuk kepedulian bagi orangtua, mengingat fenomena yang terjadi seperti gunung es dengan prevalensi yang meningkat setiap tahun.

Penelitian tentang pencegahan KSA bagi orang tua jarang ditemukan, terutama di Indonesia. Penelitian sebelumnya lebih fokus pada anak sebagai sasaran dalam pencegahan KSA. Tinjauan ini bertujuan untuk memetakan pencegahan terkait pelecehan seksual pada anak bagi orang tua. Pertanyaan reviewnya adalah sebagai berikut: Bagaimana upaya tidakan pencegahan orangtua dalam kasus pelecehan seksual pada anak?

\section{METODOLOGI}

Strategi pencarian menggunakan jenis scoping review dengan topik yaitu pencegahan kekerasan seksual pada anak oleh orang tua di negara Indonesia. Metode ini dipilih karena bervariatifnya sumber referensi yang digunakan dalam penelitian ini, yaitu berasal dari artikel jurnal dan official websites. Penelitian ini menggunakan PCC framework. Dalam penelitian ini PCC yang digunakan adalah P: Parents OR Mother OR Father OR Caregivers. C: Prevention OR Intervention OR Treatment OR Program AND Sexual Abuse OR Sexual trauma OR Sexual Violence OR Sexual Assault AND Children OR Child OR Childhood. C: Indonesia. Proses pencarian literatur dalam scoping review ini dilakukan pada bulan Juli 2021. Langkah pertama yang dilakukan adalah dengan memasukkan kata kunci dalam bahasa Inggris yaitu "Prevention OR Intervention OR Treatment OR Program AND Sexual Abuse OR Sexual trauma OR Sexual Violence OR Sexual Assault AND Children OR Child OR Childhood AND Indonesia" dan kata kunci dalam bahasa Indonesia yaitu "Pencegahan AND Kekerasan seksual AND Anak" ke dalam database yang ditentukan yaitu Cinahl Ebscohost, Pubmed, PyschoInfo, Google Scholar, Jurnal Unpad, dan pencarian secara manual. Hasil total dari memasukkan kata kunci ditemukan sebanyak 15.507 artikel.

Langkah selanjutnya yang dilakukan adalah artikel dispesifikasikan kembali menyesuaikan terhadap kriteria inklusi dan eklusi (tabel 1).

\section{Tabel 1. Kriteria inklusi dan ekslusi artikel}

\begin{tabular}{|c|c|c|}
\hline Kriteria & Inklusi & Eklusi \\
\hline Populasi & $\begin{array}{l}\text { Pada penelitian ini populasi yaitu orang } \\
\text { tua yang memiliki anak disemua } \\
\text { rentang usia }\end{array}$ & $\begin{array}{l}\text { Pencegahan yang dilakukan pada } \\
\text { anak, guru, dan kader masyarakat }\end{array}$ \\
\hline Konsep & $\begin{array}{l}\text { Pencegahan kekerasan seksual pada } \\
\text { anak oleh orang tua }\end{array}$ & - \\
\hline Konteks & $\begin{array}{l}\text { Kekerasan seksual pada anak dan } \\
\text { Indonesia }\end{array}$ & $\begin{array}{l}\text { Kekerasan seksual pada orang } \\
\text { dewasa, penelitian di luar negara } \\
\text { Indonesia }\end{array}$ \\
\hline Desain studi dan & Semua jenis penelitian kuantitatif. & Penelitian kualitatif/ \\
\hline Tipe Publikasi & $\begin{array}{l}\text { Akreditasi SINTA } 1-5 / \text { Memiliki nomor } \\
\text { ISSN }\end{array}$ & $\begin{array}{l}\text { proceeding/ manuskrip. SINTA } 6 \\
\text { dan tidak tercantum ISSN }\end{array}$ \\
\hline Ketersediaan & Full text dan Abstrak & - \\
\hline Bahasa & Inggris dan Indonesia & - \\
\hline
\end{tabular}

Melalui pencarian tersebut didapatkan 15.100 artikel dari database Google Scholar, 7 Cinahl, 16 Pubmed, 362 PsychoInfo, 14 Jurnal Unpad, dan 8 artikel berasal dari pencarian manual sehingga total artikel yang terkumpul dan dianalisis adalah 15.496 artikel, kemudian dilakukan penilaian sehingga terseleksi 18 artikel yang memenuhi syarat (lihat gambar 1). 


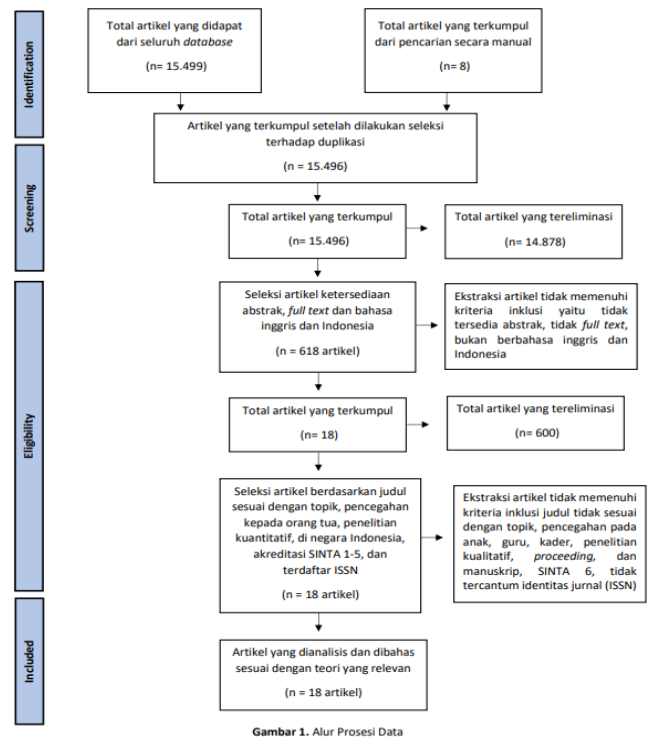

Gambar 1. Alur Prisma

Data yang telah ditemukan selanjutnya dilakukan ekstraksi yang meliputi penulis, judul, tempat, tujuan penelitian, desain, sampel, tahun penelitian, lokasi penelitian, pelaku intervensi, evaluasi dan temuan penelitian. Data yang telah terkumpul kemudian dimasukkan ke dalam tabel analisis dan dijadikan bahan acuan untuk dilakukannya pembahasan pada proses scoping review.

\section{HASIL DAN PEMBAHASAN}

\section{Karakteristik Artikel}

Sebanyak 18 artikel yang ditelaah dalam studi literatur ini. Terdapat 7 artikel desain Quasi Experiment, 6 artikel cross sectional, 1 artikel Research and Development (R\&D), 3 artikel deskriptif analisis, dan 1 artikel mengenai penelitian dan pengembangan. Tahun publikasi berkisar antara tahun 2011-2021. Artikel ini juga dilakukan di Indonesia dengan berbagai kota diantaranya Jawa Timur $(n=4)$, Jawa Tengah $(n=2)$, Daerah Istimewa Yogyakarta $(n=3)$, Sumatera Barat $(n=2)$, Sulawesi Tenggara $(n=1)$, Sulawesi Selatan $(=2)$, Kalimantan Timur $(n=1)$, Jawa Barat $(n=1)$, Sumatera Utara $(n=1)$, dan Riau $(n=1)$. Penelitian dilakukan oleh bidan $(n=3)$, dosen dan mahasiswa $(n=14)$, guru $(n=1)$. Rekapitulasi artikel hasil penelitian dapat dilihat pada tabel 2 (Lampiran 1).

\section{Bentuk Pencegahan}

Terdapat 6 bentuk pencegahan yang dapat dilakukan orang tua yaitu pemberian pendidikan kesehatan seksual pada orangtua $(n=2)$, pemberian pendidikan pencegahan kekerasan seksual pada orangtua $(n=8)$, program pendidikan keluarga $(n=1)$, pola asuh orang tua yang baik $(n=2)$, optimalisasi peran orang tua $(n=1)$, dan hubungan tingkat pendidikan dengan pengetahuan orang tua $(n=4)$.

\section{Karakteristik orang tua}

Terdapat 1.570 orang tua yang menjadi responden dalam scoping review ini. Mayoritas responden merupakan orang tua dari anak yang duduk di bangku sekolah dasar lalu diikuti orang tua dari anak yang duduk di bangku TK/PAUD.

\section{Pembahasan}

Scooping review ini bertujuan untuk memetakan pencegahan yang dilakukan orang tua untuk menghindari kejadian KSA. Berdasarkan hasil analisis pada 18 artikel ditemukan beberapa intervensi sebagai upaya pencegahan kekerasan seksual anak yang dilakukan oleh 
orang tua. Intervensi yang dapat diberikan kepada orang tua dalam mencegah terjadinya kekerasan seksual dapat dilakukan dengan memberikan pendidikan mengenai pencegahan KSA. Pendidikan KSA sangat penting untuk diterapkan sebagai dasar dalam menentukan sikap pencegahan kejadian tersebut. Idealnya orang yang lebih dewasa dalam hal ini khususnya orang tua merupakan sosok yang melindungi anak dari berbagai potensi bahaya di lingkungan sekitar. Orang tua sebagai lingkungan terdekat dari anak memiliki peran untuk membina keluarga dalam penanaman nilai agama, etik, dan moral, memperhatikan kebutuhan anak, melaksanakan peran pendampingan terhadap anak termasuk pendidikan seks pada anak sebagai upaya mencegah terjadinya kekerasan seksual pada anak. Pendidikan seks wajib diberikan orang tua serta memfasilitasi agar orang tua dapat meberikan informasi pencegahan KSA. kepada anak sedini mungkin, tepatnya dimulai saat anak berusia 3-4 tahun, karena pada usia tersebut anak sudah dapat mengerti mengenai organ tubuh mereka. Pendidikan seks pada anak dapat dilakukan secara bertahap dan diaplikasikan dalam kehidupan sehari-hari. Pada tahap awal, orang tua dapat mengenalkan identitas anak, mengenalkan perbedaan ciri-ciri tubuh anak perempuan dan laki-laki. Selanjutnya mengenalkan anatomi tubuh, hal ini dapat dilakukan ketika orang tua mengajarkan anak membersihkan alat kelaminnya sendiri setelah BAK atau BAB agar anak dapat belajar mandiri sekaligus mengajarkan anak untuk tidak sembarangan mengizinkan orang lain untuk memegang atau membersihkan alat kelaminnya (Listiyana, 2010)

Selanjutnya, secara bertahap orang tua dapat menyampaikan pendidikan seksual mengenai cara berkembang makhluk hidup dan memberikan penjelasan mengenai dampakdampak yang akan diterima apabila anak melakukan hal yang menyimpang. Namun dalam penyampaian pendidikan seksual tidak boleh terlalu vulgar tetapi harus disesuaikan dengan usia anak, karena ketika anak mulai diajarkan mengenai pendidikan seksual, anak akan kritis dan ingin tahu mengenai banyak hal. Anak juga perlu diberikan informasi secara jujur, akurat, terbuka, dan tidak menjawab pertanyaan anak dengan asal-asalan. Hal ini akan mengajarkan anak bersikap jujur dan terbuka kepada orang tuanya. Orang tua harus bersikap wajar, tidak berlebihan, rileks, menjaga intonasi suara, menghilangkan rasa risih dan takut ketika menjelaskan mengenai pendidikan seksual pada anak. Orang tua disarankan agar terlebih dahulu melepaskan persepsi seks dewasa yang erotis dan mesum ketika menginformasikan kepada anak supaya anak tidak menerima pesan dengan keliru (Listiyana, 2010)

Pemberian pendidikan kepada orang tua dapat meningkatkan pengetahuan yang berdampak pada sikap dan perilaku orang tua dalam mencegah KSA. Menurut Fatmawati \& Maulana, (2016) pemberian pendidikan kekerasan seksual pada orang tua memiliki pengaruh terhadap pengetahuan orangtua mengenai KSA, pemberian pendidikan kesehatan pada orang tua dapat meningkatkan sikap dan tindakan orang tua untuk melakukan pencegahan KSA. Banyak metode yang dapat diaplikasikan ketika memberikan pendidikan kesehatan kepada orang tua, yaitu: pemberian edukasi dengan metode "ICAS" yang mengoptimalkan peran ibu pada anak usia 4-6 tahun; buku cerita bergambar yang berjudul "ABIJAGARI (Aku Bisa Jaga Diri)" yang menjelaskan mengenai bagian tubuh yang tidak boleh disentuh, cara menolak dan melaporkan ketika anak menerima sentuhan bagian yang tidak boleh disentuh, serta pengajaran mengenai underwear rules yang mengidentifikasi mengenai 5 aspek penting pada anak yang meliputi: (a) tubuhku hanya milikku, (b) sentuhan yang baik dan sentuhan yang buruk, (c) rahasia yang baik dan rahasia yang buruk, (d) pencegahan dan perlindungan merupakan tanggung jawab orang dewasa, (e) pelaporan dan pengungkapan pelaku, baik yang dikenal, maupun tidak dikenal, serta pertolongan (Neherta \& Nurdin, (2018); Utami \& Noorratri, (2021); Justicia, (2016)).

Program pendidikan keluarga juga memiliki pengaruh dalam mencegah terjadinya KSA (Rakhmawati et al., 2018). Program pendidikan keluarga berperan dalam memberdayakan satuan pendidikan untuk melakukan kemitraan dengan orang tua serta meningkatkan kesadaran orang tua agar lebih peduli dan terlibat dalam memajukan pendidikan anak-anak mereka bekerjasama dengan satuan pendidikan dan masyarakat pegiat 
pendidikan. Sehingga diharapkan dapat tercipta keharmonisan antara keluarga, sekolah, dan masyarakat. Melihat pentingnya posisi strategis keluarga dalam pencegahan kekerasan seksual, maka setiap keluarga perlu dibekali pendidikan dalam keluarga yang akan mengoptimalkan peran keluarga dalam pengasuhan anak.

Pola asuh orang tua dapat membentuk karakter anak. Ketika pola asuh orang tua baik, maka akan melahirkan karakter anak yang baik juga (Adawiyah, 2017). Emrianti et al, (2021) menyatakan bahwa pola asuh orang tua dalam melakukan tindakan pencegahan kekerasan seksual saling berhubungan, dimana ketika pola asuh orang tua baik kepada anaknya maka tindakan dan sikapnya dalam melakukan pencegahan KSA juga akan baik, sehingga mampu melindungi anak dari perilaku kekerasan seksual. Widiana (2002 dalam Anggreni \& Notobroto, (2017) menjelaskan bahwa semakin tinggi pola asuh demokratis yang diterapkan oleh orang tua, maka semakin tinggi juga sikap kemandirian anak. Pola asuh demokratis dimaksudkan agar anak mampu membuat keputusan sendiri, bertanggung jawab, berani menyatakan pendapat, dan tetap memiliki hubungan yang hangat dengan orang tua mereka. Pola pengasuhan keluarga sangat diperlukan dalam pencegahan KSA. Pencegahan KSA. harus dimulai sedini mungkin mulai dari lingkungan keluarga (Anggreni \& Notobroto, 2017)

Peran orang tua sangat penting dalam keberlangsungan tumbuh kembang anak. Peran ini juga berpengaruh terhadap tercapainya sikap dan kebiasaan anak dalam melakukan aktivitas sehari-hari. Peran orang tua yang sangat penting ialah menjaga anaknya agar tetap dalam kondisi baik dan aman salah satunya ialah terhindar dari tindakan kekerasan seksual. Menurut Ligina, N.L (2018) menyatakan bahwa peran orang tua dalam mencegah kekerasan seksual pada anak yaitu sebagai panutan, pendidik, pendorong, pengawas, dan komunikator.

Pada intinya, secara garis besar penelitian mengenai intervensi yang dapat dilakukan sebagai upaya pencegahan kekerarasan seksual anak yang dapat dilakukan oleh orang tua diantaranya terbagi berupa pemberian pendidikan seksual kepada orang tua, pemberian pendidikan pencegahan kekerasan seksual kepada orang tua, program pendidikan keluarga, pola asuh orang tua yang baik, optimalisasi peran orang tua, dan hubungan tingkat pendidikan orang tua dengan pengetahuan mereka mengenai pencegahan kekerasan seksual.

Penelitian terkait intervensi yang dilakukan oleh orang tua dalam mencegah KSA diperlukan agar dapat membantu menyelesaikan masalah terkait KSA. Sayangnya artikel mengenai pencegahan pendidikan kekerasan seksual yang dilakukan oleh orang tua kepada anak di Indonesia masih sedikit, sehingga diperlukan penelitian lebih lanjut mengenai hal ini sebagai upaya untuk menurunkan angka kejadian kekerasan seksual pada anak di Indonesia.

\section{SIMPULAN}

Berdasarkan hasil penelitian, terdapat berbagai bentuk pencegahan KSA yang dapat dilakukan oleh orang tua kepada anak mereka dalam upaya melindung anak-anaknya dari kejahatan seksual, baik berupa peningkatan pengetahuan, perilaku, pola asuh orang tua, atau optimalisasi peran orang tua. Sayangnya belum ada penelitian yang melibatkan kesadaran orang tua dalam pencegahan KSA ini, padahal kesadaran merupakan awal seseorang termotivasi untuk melakukan suatu tindakan atau perilaku dalam melakukan pencegahan CSA. Oleh karena itu untuk penelitian selanjutnya disarankan mengeksplor kesadaran orang tua dalam pencegahan KSA.

\section{UCAPAN TERIMA KASIH}

Kami mengucapkan terima kasih kepada Universitas Padjadjaran yang telah memfasilitasi database dalam melakukan penelitian ini.

\section{DAFTAR PUSTAKA}

Adawiyah, R. (2017). Pola Asuh Orang Tua Dan Implikasinya Terhadap Pendidikan Anak. Jurnal Pendidikan Kewarganegaraan, 7(1), 33-48. 
Ajeng, Zaki, Wawan, \& Johan. (2018). Kekerasan Seksual Anak di Bawah Umur di Tinjau dari Undang - Undang Perlindungan Anak.

Anggreni, D., \& Notobroto, B. (2017). Hubungan Pola Pengasuhan Orang Tua Dengan Tindakan Pencegahan Kekerasan Seksual Pada Anak (Studi Kasus Dalam Rangka Pencegahan Kekerasan Seksual Pada Anak di Kota Mojokerto). Hospital Majapahit, 9(1), 9-17.

Emrianti, D., Lestari, H., \& Fifi, N. (2021). Hubungan Pola Asuh, Peran Masyarakat Dan Peran Petugas Kesehatan Dengan Perilaku Pencegahan Kekerasan Seksual (Pedofilia) Pada Anak Di Sdn 84 Kendari. Endemis Journal, 1.

Fatmawati, L., \& Maulana, D. (2016). Pengaruh Pendidikan Kekerasan Seksual Terhadap Perilaku Orang Tua dalam Mencegah Kekerasan Seksal Pada Anak. Journals Of Ners Community, 07(November), 188-200.

Fisnawati.S, Indriati G. \& Elita, V. (2016). Hubungan Pengetahuan Dan Sikap Orang Tua Tentang Kesehatan Seksual Pada anak usia 7-12 tahun Dalam Pencegahan Kekerasan Seksual. Jurnal Online Mahasiswa (JOM) Bidang Ilmu Keperawatan, 2, 638-646.

Ginting, M. N. ., \& Hengki, F. . (2020). Efektivitas psikoedukasi pada orang tua sebagai alternatif pencegahan kekerasan seksual pada anak. Jurnal Pionir LPPM Universitas Asahan, 7, 136-149.

Handayani, M. (2017). Pencegahan Kasus Kekerasan Seksual Pada Anak Melalui Komunikasi Antarpribadi Orang Tua Dan Anak. JIV-Jurnal Ilmiah Visi, 12(1), 67-80. https://doi.org/10.21009/JIV.1201.7

Handayani, R., \& Puspita Sari, M. (2020). Pengaruh Pendidikan Kesehatan Anak Usia Dini Terhadap Optimalisasi Peran Ibu Dalam Pencegahan Primer Kekerasan Seksual Pada $\begin{array}{lllll}\text { Anak. Jurnal } \quad \text { Kesehatan } & \text { Dr. }\end{array}$ https://doi.org/10.36858/jkds.v8i1.152

Joni, I. D. A. M., \& Surjaningrum, E. R. (2020). Psikoedukasi Pendidikan Seks Kepada Guru dan Orang Tua Sebagai Upaya Pencegahan Kekerasan Seksual Pada Anak. Jurnal Diversita, 6(1), 20-27. https:/ / doi.org/10.31289/diversita.v6i1.3582

Justicia, R. (2016). Program Underwear Rules Untuk Mencegah Universitas Pendidikan Indonesia Masa dini sering penyerapan informasi yang sangat proses Komnas tersebut jauh melebihi kenyataannya. Jurnal Pendidikan Usia Dini, 9(2), 217-232.

Ligina, N.L., D. (2018). Peran orang tua dalam pencegahan kekerasan seksual pada anak sekolah dasar di Kota Bandung. Ejournal UMM, 9(2), 109-118.

Listiyana, A. (2010). Peranan Ibu dalam Mengenalkan Pendidikan Seks pada Anak Usia Dini. Egalita Jurnal Kesetaraan dan Keadilan Gender.

Mutmainnah, \& Hasrul. (2018). Hubungan pengetahuan orang tua terhadap pencegahan pelecehan seksual pada anak. Jikp@Jurnal Ilmiah Kesehatan Pencerah, 7, 64-68.

Neherta, M., Maisa, E. A., \& Sari, Y. (2019). Intervention of sexual abuse prevention for mother of children with mental retardation in Payakumbuh Indonesia 2016. Indian Journal of Public Health Research and Development, 10(1), 461-466. https:// doi.org/10.5958/0976-5506.2019.00091.3

Neherta, M., \& Nurdin, Y. (2018). The modeling of optimizing the role of mothers as prevention of sexual violence against pre-school children in Batusangkar West Sumatra Indonesia 2017. Indian Journal of Public Health Research and Development, 9(9), 253258. https:/ / doi.org/10.5958/0976-5506.2018.01005.7

Noviana, I. (2015). Kekerasan seksual terhadap anak: dampak dan penanganannya. Sosio Informa, 1(1), 13-28. https:/ / doi.org/10.33007/inf.v1i1.87

Nurbaya, S., \& Qasim, M. (2018). Penerapan Pendidikan Seks (Underwear Rules) Terhadap Pencegahan Kekerasan Seksual Pada Anak Dan Orang Tua Di Sd Negeri 52 Welonge Kabupaten Soppeng. Media Kesehatan Politeknik Kesehatan Makassar, 13(2), 19. https://doi.org/10.32382/medkes.v13i2.612 
Olfah, Y., Ermawan, B., \& Darmawan, I. B. (2017). Gambaran Sikap Orang Tua Tentang Pencegahan Kekerasan Seksual Pada Anak Usia Prasekolah Di Dusun Pringwulung Condongcatur Sleman Yogyakarta. 6(1).

Paramastri, I., Prawitasari, J. E., Prabandari, Y. S., \& Ekowarni, E. (2014). Buklet sebagai Media Pencegahan terhadap Kekerasan Seksual pada Anak-anak. Kesmas: National Public Health Journal, 6(2), 77. https:// doi.org/10.21109/kesmas.v6i2.109

Purnamasari, D. A., \& Herfanda, E. (2019). Hubungan Tingkat Pendidikan Orang Tua Dengan Pengetahuan Tentang Kekerasan Seksual Pada Anak Usia Prasekolah Di Tk Aisyiyah Khadijah Bangunjiwo Timur Kasihan Bantul. Jurnal Kesehatan Prima, 13(1), 68. https://doi.org/10.32807/jkp.v13i1.217

Rakhmawati, E., Suyati, T., Khasanah, I., \& ... (2018). Penerapan Pendidikan Keluarga Sebagai Prevensi Kekerasan Seksual Pada Anak. ... Pendidikan Anak ..., 37-54.

Rohmah, N., Novitasari, K., Diena, U. H., Nuril, R., \& Fathul, L. N. (2015). Relasi Pelaku Korban Dan Kerentanan Pada Anak. Jurnal Psikoislamika, 5-10.

Sitompul. (2015). Kajian Hukum Tentang Tindakan Kekerasan Seksual Terhadap Anak di Indonesia. Lex Crimen, IV(1), 46-56.

Subrahmaniam, I. B. S. (2019). Faktor-Faktor Penyebab Tindak Pidana Kekerasan Seksual Terhadap Anak. Vyavahara Duta, 14(1), 1. https:// doi.org/10.25078/vd.v14i1.1097

Sulastri. (2019). Kekerasan Seksual Terhadap Anak: Relasi Pelaku- Korban, Pola Asuh Dan Kerentanan Pada Anak. Jurnal Psikologi Malahayati, 1(2), 61-71. https://doi.org/10.33024/jpm.v1i2.1961

Tamara, S. V., \& Feriani, P. (2020). Hubungan Tingkat Pengetahuan Orang Tua Tentang Pendidikan Seksual pada Anak Usia Dini dengan Perilaku Pencegahan Kekerasan Seksual pada Anak di Tk Al Jawahir Samarinda. 1(3), 1542-1546.

Utami, D. R. R. B., \& Noorratri, E. D. (2021). Prevention Children Sexual Abuse in Preschool with Picture Story Book. Gaster, 19(1), 31. https:// doi.org/10.30787/gaster.v19i1.669

WHO. (2017). Child sexual abuse. 
Lampiran 1

Tabel 2. Rekapitulasi Artikel Hasil Penelitian Intervensi Bagi Orang Tua Dalam Mencegah Kekerasan Seksual Pada Anak di Indonesia

\begin{tabular}{|c|c|c|c|c|c|c|c|c|c|c|c|}
\hline No & $\begin{array}{c}\text { Penulis, } \\
\text { tahun } \\
\text { terbit }\end{array}$ & $\begin{array}{l}\text { Tahun } \\
\text { peneli } \\
\text { tian }\end{array}$ & Judul & $\begin{array}{c}\text { Tempat } \\
\text { penelitian }\end{array}$ & Tujuan & Design & Sampel & $\begin{array}{c}\text { Pelaku } \\
\text { intervensi }\end{array}$ & $\begin{array}{c}\text { Lama } \\
\text { peneliti } \\
\text {-an } \\
\end{array}$ & Evaluasi & Temuan \\
\hline 1. & $\begin{array}{l}\text { Fatmawa } \\
\text { ti \& } \\
\text { Maulana, } \\
(2016)\end{array}$ & TD & $\begin{array}{l}\text { Pengaruh } \\
\text { Pendidikan } \\
\text { Kekerasan Seksual } \\
\text { Terhadap Perilaku } \\
\text { Orang Tua Dalam } \\
\text { Mencegah } \\
\text { Kekerasan Seksual } \\
\text { Pada Anak }\end{array}$ & $\begin{array}{l}\text { Ketapang } \\
\text { Kabupaten } \\
\text { Sampang, } \\
\text { (Jawa } \\
\text { Timur) }\end{array}$ & $\begin{array}{l}\text { Menganalisa pengaruh } \\
\text { pendidikan kekerasan } \\
\text { seksual terhadap } \\
\text { perilaku orang tua } \\
\text { dalam mencegah KSA }\end{array}$ & $\begin{array}{l}\text { Pre experiment } \\
\text { One Group } \\
\text { Pretest-Posttest }\end{array}$ & $\begin{array}{l}\text { Orang tua } \\
\text { siswa kelas } 1 \\
\text { MI } \\
\text { Tarbiyatul } \\
\text { Athfal } \\
\text { sebanyak } 36 \\
\text { orang }\end{array}$ & $\begin{array}{l}\text { Peneliti } \\
\text { (Dosen dan } \\
\text { mahasiswa } \\
\text { keperawatan } \\
\text { ) }\end{array}$ & TD & TA & $\begin{array}{l}\text { Pendidikan mengenai } \\
\text { KSA meningkatkan } \\
\text { perilaku yang baik } \\
\text { bagi orangtua } \\
\text { (pengetahuan, sikap, } \\
\text { dan tindakan } \\
\text { pencegahan KSA) }\end{array}$ \\
\hline 2. & $\begin{array}{l}\text { Handaya } \\
\text { ni \& } \\
\text { Puspita } \\
\text { Sari, } \\
(2020)\end{array}$ & 2019 & $\begin{array}{l}\text { Pengaruh } \\
\text { Pendidikan } \\
\text { Kesehatan Anak } \\
\text { Usia Dini Terhadap } \\
\text { Optimalisasi Peran } \\
\text { Ibu Dalam } \\
\text { Pencegahan Primer } \\
\text { Kekerasan Seksual } \\
\text { Pada Anak }\end{array}$ & $\begin{array}{l}\text { TK Al } \\
\text { Husna } \\
\text { Jember, } \\
\text { (Jawa } \\
\text { Timur) }\end{array}$ & $\begin{array}{l}\text { Menganalisa pengaruh } \\
\text { pendidikan seks pada } \\
\text { anak usia dini terhadap } \\
\text { optimalisasi peran } \\
\text { orang tua dalam } \\
\text { pencegahan primer } \\
\text { KSA khususnya anak } \\
\text { usia dini }\end{array}$ & $\begin{array}{l}\text { Pre experiment } \\
\text { One Group } \\
\text { Pretest-Posttest }\end{array}$ & $\begin{array}{l}45 \text { orang tua } \\
\text { siswa siswi } \\
\text { TK Al } \\
\text { Husna } \\
\text { Jember }\end{array}$ & $\begin{array}{r}\text { Peneliti } \\
\text { (Bidan) }\end{array}$ & $\mathrm{TD}$ & TA & $\begin{array}{l}\text { Pendidikan } \\
\text { Kesehatan } \\
\text { meningkatan } \\
\text { pemahaman orang } \\
\text { tua khususnya ibu } \\
\text { tentang pendidikan } \\
\text { pencegahan KSA. }\end{array}$ \\
\hline 3. & $\begin{array}{l}\text { Nurbaya } \\
\text { \& Qasim, } \\
(2018)\end{array}$ & 2018 & $\begin{array}{l}\text { Penerapan } \\
\text { Pendidikan Seks } \\
\text { (Underwear rules) to } \\
\text { Prevent Sexual } \\
\text { Violence For Children } \\
\text { And Parents at } \\
\text { Elementary School } 52 \\
\text { Welonge, Soppeng } \\
\text { District }\end{array}$ & $\begin{array}{l}\text { Welonge, } \\
\text { Soppeng, } \\
\text { (Sulawesi } \\
\text { Selatan) }\end{array}$ & $\begin{array}{l}\text { Menganalisa pengaruh } \\
\text { penerapan pendidikan } \\
\text { seks (underwear rules) } \\
\text { terhadap pencegahan } \\
\text { kekerasan seksual pada } \\
\text { anak dan orang tua di } \\
\text { SD Negeri } 52 \text { Welonge } \\
\text { Kabupaten Soppeng. }\end{array}$ & $\begin{array}{l}\text { Quasi } \\
\text { experimental } \\
\text { dengan } \\
\text { pendekatan } \\
\text { pre-post test } \\
\text { design }\end{array}$ & $\begin{array}{l}87 \text { murid } \\
\text { dan } 87 \text { orang } \\
\text { tua muri di } \\
\text { SD Negeri } \\
52 \text { Welonge, } \\
\text { Kabupaten } \\
\text { Soppeng }\end{array}$ & $\begin{array}{l}\text { Peneliti } \\
\text { (STIKES } \\
\text { Nani } \\
\text { Hasanuddin } \\
\text { Makassar) }\end{array}$ & $\begin{array}{l}3 \text { bulan } \\
\text { (Mei- } \\
\text { Juli } \\
2018 \text { ) }\end{array}$ & TA & $\begin{array}{l}\text { Program Underwear } \\
\text { rules memudahkan } \\
\text { orang tua untuk } \\
\text { membuka diskusi } \\
\text { mengenai pendidikan } \\
\text { seks dengan anak, } \\
\text { sehingga diharapkan } \\
\text { dapat anak dapat } \\
\text { melakukan } \\
\text { perlindungan diri } \\
\text { dari orang-orang } \\
\text { yang berniat }\end{array}$ \\
\hline
\end{tabular}


Intervensi Bagi Orang Tua dalam Mencegah Kekerasan Seksual Anak di Indonesia: Scoping Review

DOI: 10.31004/obsesi.v6i3.1914

\begin{tabular}{|c|c|c|c|c|c|c|c|c|c|c|c|}
\hline No & $\begin{array}{c}\text { Penulis, } \\
\text { tahun } \\
\text { terbit }\end{array}$ & $\begin{array}{c}\text { Tahun } \\
\text { peneli } \\
\text { tian }\end{array}$ & Judul & $\begin{array}{l}\text { Tempat } \\
\text { penelitian }\end{array}$ & Tujuan & Design & Sampel & $\begin{array}{c}\text { Pelaku } \\
\text { intervensi }\end{array}$ & $\begin{array}{c}\text { Lama } \\
\text { peneliti } \\
\text {-an }\end{array}$ & Evaluasi & Temuan \\
\hline 4. & $\begin{array}{l}\text { Rakhma } \\
\text { wati et al } \\
(2018)\end{array}$ & $\begin{array}{l}\text { Tidak } \\
\text { di } \\
\text { cantu } \\
\text { mkan }\end{array}$ & $\begin{array}{l}\text { Penerapan } \\
\text { Pendidikan } \\
\text { Keluarga Sebagai } \\
\text { Prevensi Kekerasan } \\
\text { Seksual Pada Anak }\end{array}$ & $\begin{array}{l}\text { PAUD di } \\
\text { Kecamatan } \\
\text { Semarang } \\
\text { Utara, } \\
\text { (Jawa } \\
\text { Tengah) }\end{array}$ & $\begin{array}{l}\text { Menganalisa pola } \\
\text { pendidikan keluarga, } \\
\text { profil pemahaman } \\
\text { orangtua mengenai } \\
\text { KSA dan keefektifan } \\
\text { program pendidikan } \\
\text { keluarga sebagai upaya } \\
\text { prevensi KSA. }\end{array}$ & $\begin{array}{l}\text { Research and } \\
\text { Development } \\
(\mathrm{R} \& \mathrm{D})\end{array}$ & $\begin{array}{l}30 \text { orangtua } \\
\text { siswa PAUD } \\
\text { dan guru } \\
\text { PAUD di } \\
\text { Kecamatan } \\
\text { Semarang } \\
\text { Utara }\end{array}$ & $\begin{array}{l}\text { Peneliti } \\
\text { (Guru ) }\end{array}$ & TD & TA & $\begin{array}{l}\text { melakukan kejahatan } \\
\text { seksual. } \\
\text { Perlunya dilakukan } \\
\text { usaha prevensi agar } \\
\text { anak tidak menjadi } \\
\text { korban, dan } \\
\text { menumbuhkan sikap } \\
\text { berani untuk melapor } \\
\text { apabila terjadi atau } \\
\text { menjadi korban KSA. } \\
\text { Serta mencegah anak } \\
\text { menjadi pelaku KSA } \\
\text { dengan pembinaan } \\
\text { orang tua, menjalin } \\
\text { hubungan orang tua } \\
\text { dan anak yang baik, } \\
\text { mengerti tumbuh dan } \\
\text { kembang anak, } \\
\text { pembinaan keluarga, } \\
\text { masyarakat dan } \\
\text { budaya }\end{array}$ \\
\hline 5. & $\begin{array}{l}\text { Joni \& } \\
\text { Surjaning } \\
\text { rum, } \\
(2020)\end{array}$ & 2019 & $\begin{array}{l}\text { Psikoedukasi } \\
\text { Pendidikan Seks } \\
\text { Kepada Guru dan } \\
\text { Orang Tua Sebagai } \\
\text { Upaya Pencegahan } \\
\text { Kekerasan Seksual } \\
\text { Pada Anak }\end{array}$ & $\begin{array}{l}\text { Ploso, Jawa } \\
\text { Timur }\end{array}$ & $\begin{array}{l}\text { Menganalisa efektivitas } \\
\text { pendidikan seks pada } \\
\text { orangtua dalam } \\
\text { meningkatkan } \\
\text { pemahaman dan } \\
\text { keterampilan orang tua } \\
\text { terkait upaya } \\
\text { pencegahan KSA }\end{array}$ & $\begin{array}{l}\text { Kuantitatif } \\
\text { Eksperimen }\end{array}$ & 15 & $\begin{array}{l}\text { Peneliti } \\
\text { (Dosen dan } \\
\text { Mahasiswa } \\
\text { Fak. } \\
\text { Psikologi, } \\
\text { Unair) }\end{array}$ & $\mathrm{TD}$ & TA & $\begin{array}{l}\text { Psikoedukasi } \\
\text { pendidikan seks } \\
\text { efektif untuk } \\
\text { meningkatkan } \\
\text { pemahaman orang } \\
\text { tua dalam upaya } \\
\text { pencegahan KSA. }\end{array}$ \\
\hline 6. & $\begin{array}{l}\text { Utami \& } \\
\text { Noorratri } \\
,(2021)\end{array}$ & 2020 & $\begin{array}{l}\text { Prevention Children } \\
\text { Sexual Abuse in } \\
\text { Preschool with } \\
\text { Picture Story Book }\end{array}$ & $\begin{array}{l}\text { TK } \\
\text { Aisyiyah } 3 \\
\text { Ngringo, } \\
\text { TK } \\
\text { Pembina } \\
\text { and TK } \\
\end{array}$ & $\begin{array}{l}\text { Untuk menghasilkan } \\
\text { buku bergambar } \\
\text { sebagai upaya } \\
\text { pencegahan KSA }\end{array}$ & $\begin{array}{l}\text { Penelitian dan } \\
\text { Pengembanga } \\
\mathrm{n} \\
\text { dengan tahap : } \\
\text { Persiapan, } \\
\text { Pelaksanaan, } \\
\end{array}$ & $\begin{array}{l}\text { Responden } \\
\text { dalam } \\
\text { pengumpul } \\
\text { an data } \\
\text { yaitu guru } \\
\text { dan } \\
\end{array}$ & $\begin{array}{l}\text { Peneliti } \\
\text { (Dosen } \\
\text { Univ. } \\
\text { Aisyiyah } \\
\text { Surakarta) }\end{array}$ & TD & TA & $\begin{array}{l}\text { Guru: } \\
\text { Tidak ada media } \\
\text { tertentu yang } \\
\text { digunakan guru } \\
\text { untuk mengajar } \\
\text { pendidikan tentang }\end{array}$ \\
\hline
\end{tabular}


Intervensi Bagi Orang Tua dalam Mencegah Kekerasan Seksual Anak di Indonesia: Scoping Review

\begin{tabular}{|c|c|c|c|c|c|c|c|c|c|c|c|}
\hline \multicolumn{12}{|c|}{ DOI: 10.31004/obsesi.v6i3.1914 } \\
\hline No & $\begin{array}{c}\text { Penulis, } \\
\text { tahun } \\
\text { terbit }\end{array}$ & $\begin{array}{c}\text { Tahun } \\
\text { peneli } \\
\text { tian }\end{array}$ & Judul & $\begin{array}{c}\text { Tempat } \\
\text { penelitian }\end{array}$ & Tujuan & Design & Sampel & $\begin{array}{c}\text { Pelaku } \\
\text { intervensi }\end{array}$ & $\begin{array}{c}\text { Lama } \\
\text { peneliti } \\
\text {-an }\end{array}$ & Evaluasi & Temuan \\
\hline & & & & $\begin{array}{l}\text { Indriyasan } \\
\text { a } \\
\text { (Jawa } \\
\text { Tengah) }\end{array}$ & & $\begin{array}{l}\text { dan } \\
\text { Penghentian }\end{array}$ & $\begin{array}{l}\text { orangtua } \\
\text { usia pra- } \\
\text { sekolah (TK) } \\
\text { dari } 3 \\
\text { sekolah } \\
\text { Responden } \\
\text { hasil uji } \\
\text { coba produk } \\
36\end{array}$ & & & & $\begin{array}{l}\text { pencegahan } \\
\text { kekerasan seksual. } \\
\text { Ibu: } \\
\text { Persepsi ibu tentang } \\
\text { Buku Bergambar } \\
\text { Pencegahan KSA } \\
\text { sangat baik }\end{array}$ \\
\hline 7. & $\begin{array}{l}\text { Mutmain } \\
\text { nah \& } \\
\text { Hasrul, } \\
(2018)\end{array}$ & 2018 & $\begin{array}{l}\text { Hubungan } \\
\text { Pengetahuan Orang } \\
\text { Tua Terhadap } \\
\text { Pencegahan } \\
\text { Pelecehan Seksual } \\
\text { Pada Anak }\end{array}$ & $\begin{array}{l}\text { Sekolah } \\
\text { Dasar } \\
\text { Negeri } 12 \\
\text { Pangkajene } \\
\text { Kabupaten } \\
\text { Sidenreng } \\
\text { Rappang } \\
\text { (Sulawesi } \\
\text { Selatan) }\end{array}$ & $\begin{array}{l}\text { Mengetahui hubungan } \\
\text { pengetahuan orang tua } \\
\text { terhadap pencegahan } \\
\text { KSA }\end{array}$ & $\begin{array}{l}\text { Kuantitatif } \\
\text { dengan desain } \\
\text { deskriptif } \\
\text { analitik } \\
\text { dengan } \\
\text { pendekatan } \\
\text { cross sectional }\end{array}$ & $\begin{array}{l}40 \text { orang tua } \\
\text { kelas } 5 .\end{array}$ & $\begin{array}{l}\text { Mahasiswa } \\
\text { ners dan } \\
\text { mahasiswa } \\
\text { s1 } \\
\text { Stikes } \\
\text { Muhammadi } \\
\text { yah Sidrap }\end{array}$ & $\begin{array}{l}2 \text { bulan } \\
(25 \\
\text { maret } \\
\text { sampai } \\
\text { dengan } \\
25 \text { mei } \\
2018)\end{array}$ & TA & $\begin{array}{l}\text { Pengetahuan tidak } \\
\text { ada hubungannya } \\
\text { dengan pencegahan } \\
\text { KSA }\end{array}$ \\
\hline 8. & $\begin{array}{l}\text { Emrianti } \\
\text { et al., } \\
(2021)\end{array}$ & 2020 & $\begin{array}{l}\text { Hubungan Pola } \\
\text { Asuh, Peran } \\
\text { Masyarakat dan } \\
\text { Peran Petugas } \\
\text { Kesehatan Dengan } \\
\text { Perilaku Pencegahan } \\
\text { Kekerasan Seksual } \\
\text { (Pedofilia) Pada } \\
\text { Anak Di SDN } 84 \\
\text { Kendari }\end{array}$ & $\begin{array}{l}\text { SDN } 84 \\
\text { Kendari, } \\
\text { (Sulawesi } \\
\text { Tenggara) }\end{array}$ & $\begin{array}{l}\text { Mengetahui hubungan } \\
\text { antara pola asuh orang } \\
\text { tua, peran masyarakat } \\
\text { dan peran petugas } \\
\text { kesehatan dengan } \\
\text { perilaku pencegahan } \\
\text { kekerasan seksual } \\
\text { (pedofilia) pada anak di } \\
\text { SDN } 84 \text { Kendari }\end{array}$ & $\begin{array}{l}\text { Desain } \\
\text { kuantitatif } \\
\text { dengan } \\
\text { pendekatan } \\
\text { cross sectional } \\
\text { study }\end{array}$ & $\begin{array}{l}\text { Populasi: } \\
861 \text { orang } \\
\text { tua dari } \\
\text { siswa di } \\
\text { SDN } 84 \\
\text { Kendari } \\
\text { Sampel: } 265 \\
\text { responden }\end{array}$ & $\begin{array}{l}\text { Peneliti } \\
\text { (FKM } \\
\text { Universitas } \\
\text { Halu Oleo } \\
\text { Kendari }\end{array}$ & $\begin{array}{l}1 \text { bulan } \\
\text { (Januari } \\
- \\
\text { Februar } \\
\text { i 2020) }\end{array}$ & TA & $\begin{array}{l}\text { Terdapat hubungan } \\
\text { pemberian pola asuh } \\
\text { orang tua dengan } \\
\text { perilakunya dalam } \\
\text { melakukan } \\
\text { pencegahan KSA }\end{array}$ \\
\hline 9. & $\begin{array}{l}\text { Neherta } \\
\& \\
\text { Nurdin, } \\
(2018)\end{array}$ & 2017 & $\begin{array}{l}\text { The Modeling of } \\
\text { Optimizing the Role of } \\
\text { Mothers as Prevention } \\
\text { of Sexual Violence } \\
\text { Againts Pre-School } \\
\text { Children in }\end{array}$ & $\begin{array}{l}\text { Batusangk } \\
\text { ar, } \\
\text { Sumatra } \\
\text { Barat, }\end{array}$ & $\begin{array}{l}\text { Menetapkan model } \\
\text { pencegahan kekerasan } \\
\text { seksual pada anak } \\
\text { prasekolah oleh ibu di } \\
\text { Sumatra Barat }\end{array}$ & $\begin{array}{l}\text { Kombinasi } \\
\text { kuantitatif } \\
\text { (quasi } \\
\text { eksperimen) } \\
\text { dan kualitatif } \\
\text { dengan non- }\end{array}$ & $\begin{array}{l}180 \text { ibu dari } \\
\text { anak } \\
\text { prasekolah } \\
\text { (usia 4-6 } \\
\text { tahun) di } \\
\text { daerah }\end{array}$ & $\begin{array}{l}\text { Peneliti: } \\
\text { Dosen Fak. } \\
\text { Keperawata } \\
\text { n Univ } \\
\text { Andalas, } \\
\text { Padang }\end{array}$ & $\begin{array}{l}6 \text { bulan } \\
\text { (Juni- } \\
\text { Desemb } \\
\text { er 2017) }\end{array}$ & $\begin{array}{l}\text { Evaluasi } \\
4 \text { kali, } \\
\text { dilakuka } \\
\text { n setelah } \\
4 \text { bulan } \\
\text { dari }\end{array}$ & $\begin{array}{l}\text { Pada kelompok } \\
\text { intervensi ditemukan } \\
\text { terdapat peningkatan } \\
\text { pengetahuan dan } \\
\text { sikap ibu }\end{array}$ \\
\hline
\end{tabular}


Intervensi Bagi Orang Tua dalam Mencegah Kekerasan Seksual Anak di Indonesia: Scoping Review

DOI: 10.31004/obsesi.v6i3.1914

\begin{tabular}{|c|c|c|c|c|c|c|c|c|c|c|c|}
\hline No & $\begin{array}{c}\text { Penulis, } \\
\text { tahun } \\
\text { terbit }\end{array}$ & $\begin{array}{c}\text { Tahun } \\
\text { peneli } \\
\text { tian }\end{array}$ & Judul & $\begin{array}{c}\text { Tempat } \\
\text { penelitian }\end{array}$ & Tujuan & Design & Sampel & $\begin{array}{c}\text { Pelaku } \\
\text { intervensi }\end{array}$ & $\begin{array}{c}\text { Lama } \\
\text { peneliti } \\
\text {-an } \\
\end{array}$ & Evaluasi & Temuan \\
\hline & & & $\begin{array}{l}\text { Batusangkar West } \\
\text { Sumatra Indonesia } \\
2017\end{array}$ & & & $\begin{array}{l}\text { equivalent } \\
\text { pretest-posttest } \\
\text { control group } \\
\text { design. }\end{array}$ & $\begin{array}{l}\text { Batusangkar } \\
\text {, Sumatra } \\
\text { Barat }\end{array}$ & & & $\begin{array}{l}\text { tahap } \\
\text { intervens } \\
\text { i terakhir }\end{array}$ & \\
\hline 10 & $\begin{array}{l}\text { Tamara } \\
\& \\
\text { Feriani, } \\
(2020)\end{array}$ & 2019 & $\begin{array}{l}\text { Hubungan Tingkat } \\
\text { Pengetahuan } \\
\text { Orangtua Tentang } \\
\text { Pendidikan Seksual } \\
\text { pada Anak Usia Dini } \\
\text { Dengan Perilaku } \\
\text { Pencegahan } \\
\text { Kekerasan Sesksual } \\
\text { Pada Anak Di TK Al } \\
\text { Jawahir Samarinda }\end{array}$ & $\begin{array}{l}\text { TK Al } \\
\text { Jawahir } \\
\text { Samarinda, } \\
\text { (Kalimanta } \\
\text { n Timur) }\end{array}$ & $\begin{array}{l}\text { Mengetahui hubungan } \\
\text { tingkat pengetahuan } \\
\text { orangtua tentang } \\
\text { pendidikan seksual } \\
\text { pada anak usia dini } \\
\text { dengan perilaku } \\
\text { pencegahan KSA di TK } \\
\text { Al Jawahir Samarinda }\end{array}$ & $\begin{array}{l}\text { Deskriptif } \\
\text { kuantitatif } \\
\text { secara cross } \\
\text { sectional }\end{array}$ & 79 orangtua & $\begin{array}{l}\text { Peneliti } \\
\text { (Univ } \\
\text { Muhammadi } \\
\text { yah } \\
\text { Kalimantan } \\
\text { Timur, } \\
\text { Samarinda. }\end{array}$ & $\mathrm{TD}$ & TA & $\begin{array}{l}\text { Bimbingan dan } \\
\text { pendidikan anak } \\
\text { merupakan } \\
\text { tanggungjawab } \\
\text { orangtua terutama } \\
\text { ibu yang setiap } \\
\text { harinya berinteraksi } \\
\text { dengan anak } \\
\text { sehingga menjadi } \\
\text { pribadi yang percaya } \\
\text { diri. }\end{array}$ \\
\hline 11 & $\begin{array}{l}\text { Ginting } \\
\text { \& } \\
\text { Hengki, } \\
(2020)\end{array}$ & 2020 & $\begin{array}{l}\text { Efektivitas } \\
\text { Psikoedukasi pada } \\
\text { Orang Tua sebagai } \\
\text { Alternatif } \\
\text { Pencegahan } \\
\text { Kekerasan Seksual } \\
\text { pada Anak }\end{array}$ & $\begin{array}{l}\text { Indonesia } \\
\text { (Sumatera } \\
\text { Utara) }\end{array}$ & $\begin{array}{l}\text { Menganalisa efektivitas } \\
\text { psikoedukasi pada } \\
\text { orang tua sebagai } \\
\text { upaya pencegahan KSA } \\
\text { untuk meningkatkan } \\
\text { keterampilan } \\
\text { keselamatan pribadi }\end{array}$ & $\begin{array}{l}\text { Quasi } \\
\text { eksperiment }\end{array}$ & $\begin{array}{l}18 \text { orang tua } \\
\text { dari anak SD } \\
\text { kelas } 4-5\end{array}$ & $\begin{array}{l}\text { Peneliti } \\
\text { (Dosen } \\
\text { Institut } \\
\text { Kesehatan } \\
\text { Deli Husada } \\
\text { Deli Tua) }\end{array}$ & $\begin{array}{l}2 \\
\text { minggu }\end{array}$ & $\begin{array}{l}\text { Evaluasi } \\
\text { diberikan } \\
2 \text { minggu } \\
\text { setelah } \\
\text { pemberia } \\
\text { n post- } \\
\text { test }\end{array}$ & $\begin{array}{l}\text { Psikoedukasi pada } \\
\text { orang tua efektif } \\
\text { dalam meningkatkan } \\
\text { keterampilan } \\
\text { keselamatan pribadi } \\
\text { pada anak dalam } \\
\text { mencegah KSA }\end{array}$ \\
\hline 12 & $\begin{array}{l}\text { Fisnawati } \\
\text {.S, } \\
\text { Indriati } \\
\text { G. \& } \\
\text { Elita, V } \\
\text { (2016) }\end{array}$ & $\begin{array}{l}\text { Desem } \\
\text { ber } \\
2014 \\
\text { sampa } \\
\text { i bulan } \\
\text { Januar } \\
\text { i } 2015\end{array}$ & $\begin{array}{l}\text { Hubungan } \\
\text { pengetahuan orang } \\
\text { tua tentang } \\
\text { kesehatan seksual } \\
\text { pada anak usia } 7-12 \\
\text { tahun dengan sikap } \\
\text { orang tua dalam } \\
\text { pencegahan } \\
\text { kekerasan seksual }\end{array}$ & $\begin{array}{l}\text { Pekanbaru } \\
\text { (Riau), }\end{array}$ & $\begin{array}{l}\text { Mengetahui hubungan } \\
\text { pengetahuan orang tua } \\
\text { tentang kesehatan } \\
\text { seksual pada anak usia } \\
7-12 \text { tahun dengan } \\
\text { sikap orang tua dalam } \\
\text { pencegahan KSA }\end{array}$ & $\begin{array}{l}\text { Deskriptif } \\
\text { korelasi } \\
\text { dengan } \\
\text { pendekatan } \\
\text { cross sectional. }\end{array}$ & $\begin{array}{l}369 \text { orang } \\
\text { tua. }\end{array}$ & $\begin{array}{l}\text { Penulis } \\
\text { (Mahasiswa } \\
\text { / Perawat } \\
\text { RSUD Indra } \\
\text { Sari Rengat, } \\
\text { Riau dan } \\
\text { PSIK } \\
\text { Universitas } \\
\text { Riau). }\end{array}$ & 2 Bulan & TA & $\begin{array}{l}\text { Terdapat hubungan } \\
\text { antara pengetahuan } \\
\text { orang tua tentang } \\
\text { kesehatan seksual } \\
\text { anak usia } 7-12 \text { tahun } \\
\text { dengan sikap orang } \\
\text { tua dalam } \\
\text { pencegahan KSA }\end{array}$ \\
\hline 13 & $\begin{array}{l}\text { Paramast } \\
\text { ri et al., } \\
(2014)\end{array}$ & $\begin{array}{l}\text { Tidak } \\
\text { dicant } \\
\text { umkan }\end{array}$ & $\begin{array}{l}\text { Buklet sebagai } \\
\text { Media Pencegahan } \\
\text { terhadap Kekerasan }\end{array}$ & $\begin{array}{l}\text { Daerah } \\
\text { Istimewa }\end{array}$ & $\begin{array}{l}\text { Menguji apakah media } \\
\text { buklet dapat dipakai } \\
\text { sebagai alat }\end{array}$ & $\begin{array}{l}\text { Analisis } \\
\text { deskriptif }\end{array}$ & $\begin{array}{l}\text { para ahli } \\
\text { media yang }\end{array}$ & $\begin{array}{l}\text { Penulis } \\
\text { (Mahasiswa } \\
\text { psikologi }\end{array}$ & $\mathrm{TD}$ & TA & $\begin{array}{l}\text { Medium buklet dapat } \\
\text { diterapkan pada } \\
\text { siswa SD sebagai alat }\end{array}$ \\
\hline
\end{tabular}


Intervensi Bagi Orang Tua dalam Mencegah Kekerasan Seksual Anak di Indonesia: Scoping Review

\begin{tabular}{|c|c|c|c|c|c|c|c|c|c|c|c|}
\hline \multicolumn{12}{|c|}{ DOI: 10.31004/obsesi.v6i3.1914 } \\
\hline No & $\begin{array}{c}\text { Penulis, } \\
\text { tahun } \\
\text { terbit }\end{array}$ & $\begin{array}{c}\text { Tahun } \\
\text { peneli } \\
\text { tian }\end{array}$ & Judul & $\begin{array}{c}\text { Tempat } \\
\text { penelitian }\end{array}$ & Tujuan & Design & Sampel & $\begin{array}{l}\text { Pelaku } \\
\text { intervensi }\end{array}$ & $\begin{array}{c}\text { Lama } \\
\text { peneliti } \\
\text {-an }\end{array}$ & Evaluasi & Temuan \\
\hline & & & $\begin{array}{l}\text { Seksual pada Anak- } \\
\text { anak }\end{array}$ & $\begin{array}{l}\text { Yogyakart } \\
\text { a, }\end{array}$ & $\begin{array}{l}\text { pencegahan KSA, } \\
\text { khususnya bagi siswa } \\
\text { sekolah dasar (SD) }\end{array}$ & & $\begin{array}{l}\text { berjumlah } 4 \\
\text { orang }\end{array}$ & $\begin{array}{l}\text { dan } \\
\text { kedokteran } \\
\text { universitas } \\
\text { gadjah } \\
\text { mada) }\end{array}$ & & & $\begin{array}{l}\text { pendukung } \\
\text { pencegahan KSA. }\end{array}$ \\
\hline 14 & $\begin{array}{l}\text { Olfah et } \\
\text { al., (2017) }\end{array}$ & 2017 & $\begin{array}{l}\text { Gambaran Sikap } \\
\text { Orang Tua Tentang } \\
\text { Pencegahan } \\
\text { Kekerasan Seksual } \\
\text { Pada Anak Usia } \\
\text { Prasekolah Di } \\
\text { Dusun Pringwulung } \\
\text { Condongcatur } \\
\text { Sleman Yogyakarta }\end{array}$ & $\begin{array}{l}\text { Dusun } \\
\text { Pringwulu } \\
\text { ng } \\
\text { Condongca } \\
\text { tur } \\
\text { (Daerah } \\
\text { Istimewa } \\
\text { Yogyakart } \\
\text { a) }\end{array}$ & $\begin{array}{l}\text { Mengetahui sikap } \\
\text { orang tua tentang } \\
\text { pencegahan KSA usia } \\
\text { prasekolah }\end{array}$ & $\begin{array}{l}\text { Penelitian } \\
\text { deskriptif } \\
\text { dengan } \\
\text { metode survey }\end{array}$ & $\begin{array}{l}\text { Orang tua } \\
\text { yang } \\
\text { memiliki } \\
\text { anak usia } \\
\text { prasekolah } \\
\text { di Dusun } \\
\text { Pringwulun } \\
\text { g sebanyak } \\
51 \text { orang tua }\end{array}$ & $\begin{array}{l}\text { Peneliti } \\
\text { (Perawat) }\end{array}$ & $\mathrm{TD}$ & TA & $\begin{array}{l}\text { Gambaran sikap } \\
\text { orang tua tentang } \\
\text { pencegahan } \\
\text { kekerasan KSA usia } \\
\text { prasekolah mayoritas } \\
\text { memiliki sikap yang } \\
\text { positif }\end{array}$ \\
\hline 15 & $\begin{array}{l}\text { Neherta } \\
\text { et al.,( } \\
2019)\end{array}$ & 2016 & $\begin{array}{l}\text { Intervention of } \\
\text { Sexual Abuse } \\
\text { Prevention for } \\
\text { Mother of Children } \\
\text { with Mental } \\
\text { Retardation in } \\
\text { Payakumbuh } \\
\text { Indonesia } 2016\end{array}$ & $\begin{array}{l}\text { Child Care } \\
\text { Foundation } \\
\text { SLB-PAB } \\
\text { Payakumb } \\
\text { uh } \\
\text { (Sumatra } \\
\text { Barat) }\end{array}$ & $\begin{array}{l}\text { Menganalisa pengaruh } \\
\text { intervensi terhadap } \\
\text { peningkatan } \\
\text { pengetahuan tentang } \\
\text { pencegahan KSA } \\
\text { terhadap anak } \\
\text { tunagrahita.. }\end{array}$ & $\begin{array}{l}\text { Pre experiment } \\
\text { One Group } \\
\text { Pretest-Posttest }\end{array}$ & $\begin{array}{l}45 \text { ibu yang } \\
\text { memiliki } \\
\text { anak } \\
\text { retardasi } \\
\text { mental. }\end{array}$ & $\begin{array}{l}\text { Peneliti } \\
\text { (Profesi } \\
\text { tidak } \\
\text { dicantumka } \\
\text { n) }\end{array}$ & $\begin{array}{l}\text { May } \\
2016 \text { - } \\
\text { January } \\
2017\end{array}$ & TA & $\begin{array}{l}\text { Intervensi membantu } \\
\text { meningkatkan sikap } \\
\text { ibu tentang } \\
\text { pencegahan KSA } \\
\text { anak tunagrahita. }\end{array}$ \\
\hline 16 & $\begin{array}{l}\text { Purnama } \\
\text { sari \& } \\
\text { Herfanda } \\
\text {, (2019) }\end{array}$ & 2018 & $\begin{array}{l}\text { Hubungan Tingkat } \\
\text { Pendidikan Orang } \\
\text { Tua Dengan } \\
\text { Pengetahuan } \\
\text { Tentang Kekerasan } \\
\text { Seksual Pada Anak } \\
\text { Usia Prasekolah Di } \\
\text { Tk Aisyiyah } \\
\text { Khadijah } \\
\text { Bangunjiwo Timur } \\
\text { Kasihan Bantul }\end{array}$ & $\begin{array}{l}\text { TK } \\
\text { Aisyiyah } \\
\text { Khadijah } \\
\text { Bangunjiw } \\
\text { o Timur } \\
\text { (DIY } \\
\text { Yogyakart } \\
\text { a) }\end{array}$ & $\begin{array}{l}\text { Mengetahui hubungan } \\
\text { tingkat pendidikan } \\
\text { orang tua dengan } \\
\text { pengetahuan tentang } \\
\text { KSA pada anak usia } \\
\text { prasekolah di tk } \\
\text { aisyiyah khadijah } \\
\text { bangunjiwo timur }\end{array}$ & $\begin{array}{l}\text { kuantitatif } \\
\text { dengan } \\
\text { metode } \\
\text { korelasional }\end{array}$ & $\begin{array}{l}84 \text { orang tua } \\
\text { yang } \\
\text { memiliki } \\
\text { anak usia } \\
\text { prasekolah } \\
\text { (3-6 tahun) } \\
\text { di TK } \\
\text { Aisyiyah } \\
\text { Khadijah } \\
\text { Bangunjiwo } \\
\text { Timu }\end{array}$ & $\begin{array}{l}\text { Peneliti } \\
\text { (Jurusan } \\
\text { Kebidanan, } \\
\text { Univ'Aisyiy } \\
\text { ah } \\
\text { Yogyakarta) }\end{array}$ & $\mathrm{TD}$ & TA & $\begin{array}{l}\text { Terdapat hubungan } \\
\text { antara tingkat } \\
\text { pendidikan orang tua } \\
\text { dengan pengetahuan } \\
\text { tentang KSA anak } \\
\text { usia prasekolah }\end{array}$ \\
\hline
\end{tabular}


Intervensi Bagi Orang Tua dalam Mencegah Kekerasan Seksual Anak di Indonesia: Scoping Review

DOI: 10.31004/obsesi.v6i3.1914

\begin{tabular}{|c|c|c|c|c|c|c|c|c|c|c|c|}
\hline No & $\begin{array}{c}\text { Penulis, } \\
\text { tahun } \\
\text { terbit }\end{array}$ & $\begin{array}{c}\text { Tahun } \\
\text { peneli } \\
\text { tian }\end{array}$ & Judul & $\begin{array}{c}\text { Tempat } \\
\text { penelitian }\end{array}$ & Tujuan & Design & Sampel & $\begin{array}{c}\text { Pelaku } \\
\text { intervensi }\end{array}$ & $\begin{array}{c}\text { Lama } \\
\text { peneliti } \\
\text {-an } \\
\end{array}$ & Evaluasi & Temuan \\
\hline 17 & $\begin{array}{l}\text { Ligina, } \\
\text { N.L., } \\
\text { (2018) }\end{array}$ & 2018 & $\begin{array}{l}\text { Peran Orang Tua } \\
\text { dalam Pencegahan } \\
\text { Kekerasan Seksual } \\
\text { pada Anak Sekolah } \\
\text { Dasar di Kota } \\
\text { Bandung }\end{array}$ & $\begin{array}{l}\text { Indonesia } \\
\text { (SDN 061 } \\
\text { Cijerah, } \\
\text { Kota } \\
\text { Bandung), } \\
\text { Jawa Barat }\end{array}$ & $\begin{array}{l}\text { Mendapatkan } \\
\text { gambaran tentang } \\
\text { peran orang tua dalam } \\
\text { pencegahan KSAv di } \\
\text { SDN di Kota Bandung }\end{array}$ & $\begin{array}{l}\text { Deskriptif } \\
\text { kuantitatif }\end{array}$ & $\begin{array}{l}141 \text { orang } \\
\text { tua }\end{array}$ & $\begin{array}{l}\text { Peneliti: } \\
\text { Mahasiswa } \\
\text { dan Dosen } \\
\text { Fak } \\
\text { Keperawata } \\
\text { n Univ } \\
\text { Padjadjaran }\end{array}$ & $\mathrm{TD}$ & TA & $\begin{array}{l}\text { Peran orang tua } \\
\text { dalam pencegahan } \\
\text { KSA mayoritas } \\
\text { berkatagori baik. }\end{array}$ \\
\hline 18 & $\begin{array}{l}\text { Anggreni } \\
\& \\
\text { Notobrot } \\
\text { o, (2017) }\end{array}$ & 2016 & $\begin{array}{l}\text { Hubungan Pola } \\
\text { Pengasuhan Orang } \\
\text { Tua Dengan } \\
\text { Tindakan } \\
\text { Pencegahan } \\
\text { Kekerasan Seksual } \\
\text { Pada Anak }\end{array}$ & $\begin{array}{l}\text { Mojokerto, } \\
\text { Jawa } \\
\text { Timur, }\end{array}$ & $\begin{array}{l}\text { Menganalisis } \\
\text { hubungan pola asuh } \\
\text { orang tua dengan } \\
\text { perilaku kesehatan } \\
\text { reproduksi anak- } \\
\text { anak dalam rangka } \\
\text { mencegah KSA di } \\
\text { Mojokerto }\end{array}$ & cross sectional & $\begin{array}{l}103 \text { orang } \\
\text { tua }\end{array}$ & $\begin{array}{l}\text { Peneliti } \\
\text { :Dosen Prodi } \\
\text { DIII } \\
\text { kebidanan } \\
\text { Poltekkes } \\
\text { Majapahit, } \\
\text { Dosen } \\
\text { Program } \\
\text { Studi } \\
\text { Magister } \\
\text { IKM_FKM } \\
\text { Unair }\end{array}$ & $\mathrm{TD}$ & TA & $\begin{array}{l}\text { Ada hubungan antara } \\
\text { pola pengasuhan } \\
\text { orangtua dengan } \\
\text { tindakan pencegahan } \\
\text { KSA }\end{array}$ \\
\hline
\end{tabular}

Keterangan: $\mathrm{TD}=$ Tidak Tiketahui, $\mathrm{TA}=$ Tidak Ada, FKM= Fakultas Kesehatan Masyarakat, Unair= Universitas Airlangga,Univ $=$ Universitas, Fak Kep= Fakultas Keperawatan, Stikes=Sekolah Tinggi Ilmu Kesahatn, PSIK= Dosen Program Studi Ilmu Keperawatan, IKM= Ilmu Kesehatan Masyarakat 